Instructions for authors, subscriptions and further details:

http://brac.hipatiapress.com

\title{
Aurora Leal. Pensar el Pensamiento. Un Estudio sobre el Respeto, el Reconocimiento y la Escucha Mediante Dibujo y Expresión Corporal Víctor Cabré ${ }^{1}$
}

1) Fundació Vidal i Barraquer, Universitat Ramon Llull. Barcelona (Spain)

Date of publication: February $3^{\text {rd }}, 2022$

Edition period: February 2022 - June 2022

To cite this article: Cabré, V. (2022). Aurora Leal. Pensar el Pensamiento. Un Estudio sobre el Respeto, el Reconocimiento y la Escucha Mediante Dibujo y Expresión Corporal. Barcelona, Research, Art, Creation, 10(1) 100103. doi: $10.17583 /$ brac. 8297

To link this article: http://dx.doi.org/10.17583/brac.8722

\section{PLEASE SCROLL DOWN FOR ARTICLE}

The terms and conditions of use are related to the Open Journal System and to Creative Commons Attribution License (CC-BY). 
BRAC - Barcelona Research Art Creation. Vol. 10 No. 1, February 2022, pp. 100-103

(Recibido: 2 julio 2021; Aceptado: 21 julio 2021; Publicado: 3 febrero 2022)

\section{Review}

\section{AURORA LEAL. Pensar el Pensamiento. Un Estudio sobre el Respeto, el Reconocimiento y la Escucha Mediante Dibujo y Expresión Corporal. Ed. Octaedro, 2020. Barcelona.}

Aurora Leal nos propone un descentramiento en lo que al hecho de pensar se refiere. Algo que se nos aparece tan simple y habitual como el pensar, a menudo como algo automático -a la manera del respirar, no podemos no pensar- se convierte en objeto de estudio y análisis por parte de la autora.

A través de un aparentemente sencillo estudio realizado con estudiantes del Máster de Danza Movimiento Terapia, Leal nos propone la tarea de comprender un poco más acerca de qué pensamos y en cómo lo hacemos.

Desde un buen inicio, nos sorprende ya confrontándonos con la idea, comúnmente aceptada, de que pensamos con la cabeza. Si bien es obvio que alteraciones cerebrales afectarán, entre otras, áreas cruciales del curso o el contenido del pensamiento, no es menos cierto que se trata de una función suficientemente compleja como para concluir que, en ella, están implicadas una gran cantidad de estructuras diferentes, además de las cerebrales. Se podría decir que no pensamos sólo con "la cabeza", o con el cerebro o con la mente; pensamos con todo el cuerpo, al igual que sentimos con todo el cuerpo, o nos emocionamos con todo el cuerpo o, incluso, aprendemos con todo el cuerpo. Neurocientíficos actuales, como el premio Nobel Eric Kandel, nos advierte, también, del riesgo de ciertos reduccionismos: "Entender la biología del cerebro no niega la riqueza ni la complejidad del pensamiento. Al contrario, al centrarse en un componente de un proceso mental, la reducción puede expandir nuestra visión y permitirnos percibir relaciones antes imprevistas entre fenómenos biológicos y psicológicos" (Kandel, 2013, p. 550). 
El trabajo de Leal está estructurado en base a dos ejes que se superponen. El primero es un eje que discurre desde dentro hacia fuera; desde el interior del sujeto (lo intrapsíquico) hacia el exterior, los demás (lo relacional). De esta forma, los tres primeros capítulos constituyen un bloque que se centra en la comprensión de la función de pensar: qué pensamos, cómo pensamos y sobre todo desde dónde pensamos. Para ello, la autora bebe de las fuentes de pensadores que se mueven en la frontera de la filosofía, la antropología humana y la psicología, muy en la línea de los propios conocimientos e intereses de la autora. Mediante una exposición clara y directa, que no rehúye en ningún momento la profundidad en una temática altamente compleja, la narración transita por las cualidades icónicas, metafóricas y simbólicas del pensamiento, que incluyen el lenguaje, la grafía y el movimiento como expresiones privilegiadas.

A partir de esta sólida base conceptual, la autora se adentra en el campo de lo relacional y lo hace sirviéndose de tres capacidades/cualidades que imprimen carta de naturaleza a buena parte de las relaciones humanas más significativas: la escucha, el reconocimiento y el respeto. Gracias al dibujo y al movimiento corporal podemos ir delimitando estos tres conceptos, ampliamente ejemplificados a lo largo del libro.

El segundo eje que configura la arquitectura de la obra, complementa perfectamente al que acabamos de exponer y se podría resumir diciendo que, la autora, se desliza coherentemente de la teoría a la práctica. Efectivamente, si la primera parte supone un gran esfuerzo de conceptualización en procesos intra e interindividuales complejos, la segunda parte nos ofrece la propia experiencia de la autora, junto a un grupo de estudiantes, en la expresión a través del cuerpo, el dibujo y el lenguaje. Bellamente referenciada -el libro incluye dibujos y textos con expresiones literales de las estudiantes- la obra nos muestra el proceso de elaboración con rigor y detalle, lo que permite que el lector incorpore nuevos matices en su comprensión. Además, la experiencia relatada en esta parte nos permite tener acceso a otras notables cualidades de la autora, como la creatividad y la sensibilidad en su función docente y transformadora con las estudiantes.

Es así como Aurora Leal nos ofrece un bello y magnífico ejemplo de que, "en lugar de decir que sabemos, deberíamos decir que vamos sabiendo"; de que en lugar de considerar que el movimiento o el dibujo son producto de lo que tenemos en nuestro pensamiento, forman parte activa en el proceso de "construir" ese pensamiento.

De esta forma, podríamos acercarnos a cualquier producción artística, no como resultado, sino como parte de un proceso "en construcción". Cuando 
analiza el desarrollo que tiene lugar desde la idea inicial, al concepto relacional y a su expresión (gráfica o corporal), Leal nos muestra que el proceso no se detiene ahí, sino que continua indefinidamente retroalimentándose. La acción de dibujar expresa un pensamiento pero, a su vez, lo modifica, incorpora nuevos matices, enfrenta contradicciones y se nos aparece, ahora, no sólo como el resultado de unos contenidos pensados o sentidos por el autor, sino como el pensamiento mismo. A pesar de que la obra puede haber quedado "terminada" o fijada en el tiempo, no ha perdido esa cualidad de movimiento, de eslabón en un proceso que todavía sigue activo. Me atrevería a decir que éste sería uno de los cometidos del observador/espectador, el de coger el relevo en este proceso de "continuar" algo que, tal vez, el autor ha detenido o interrumpido, en la línea de lo que ya sugerían Ernst Kris y Ernst Gombrich en su fecunda colaboración y que sigue ocupando la moderna psicología cognitiva: analizar el proceso por el que el observador transforma la información sensorial en percepción, emoción, empatía y acción en un contexto cultural determinado.

La autora, doctora en psicología y especializada en los procesos evolutivos del ser humano, mantiene una actitud filosófica ante la vida. En palabras del filósofo francés Michel Onfray "todos nacemos filósofos, pero solo unos pocos tienen la suerte de seguir siéndolo cuando crecen”. Aurora Leal es una de esas personas que mantienen intacta la curiosidad como motor que la impulsa al conocimiento, incluso de fenómenos complejos como el que enfrenta en esta obra. Gracias a sus intereses amplios y diversificados -que incluyen las artes, además de la psicología- puede acometer la tarea de sistematizar y ejemplificar la compleja función del pensar. Y no sólo lo hace mediante su propia capacidad de pensar, sino de hacerlo "bien", mediante un pensamiento crítico que remueve y no deja de cuestionar al lector. Como diría José Carlos Ruíz, filósofo cordobés, "pensar bien es un arte y necesita muchas horas de trabajo y esfuerzo" y reconoce que "actualmente se encuentra en peligro de extinción" (2018); pero una vez hemos podido acceder a este pensamiento crítico nos acompaña durante toda la vida. 


\section{Referencias}

Kandel, E. R. (2013). La era del inconsciente. La exploración del inconsciente en el arte, la mente y el cerebro. Ed. Paidós.

Ruíz, J. C. (2018). El arte de pensar. Cómo los grandes filósofos pueden estimular nuestro pensamiento crítico. Ed. Almuzara.

Víctor Cabré: Doctor en psicología. Institut Universitari de Salut Mental Vidal i Barraquer. Universitat Ramon Llull. Barcelona

Email address: vcabre@fvb.cat

Contact Address: c/ Sant Gervasi de Cassoles 88-90. 08022 Barcelona 